Review Article

\title{
A State-of-the-Art Review on Hybrid GFRP-Concrete Bridge Deck Systems
}

\author{
Yize Zuo $\mathbb{D}^{1},{ }^{1,2}$ Yuqi Cao $\mathbb{D D}^{1,2}$ Yuqi Zhou ${ }^{1}{ }^{1}$ and Wei Wei Liu ${ }^{1}{ }^{1}$ \\ ${ }^{1}$ China Construction First Group Construction \& Development Co, Ltd., Beijing, China \\ ${ }^{2}$ China State Construction Engineering Corporation, Beijing, China \\ Correspondence should be addressed to Yuqi Zhou; zhouyuqidoc@163.com
}

Received 23 February 2021; Revised 30 April 2021; Accepted 19 May 2021; Published 30 May 2021

Academic Editor: Shengwen Tang

Copyright $\left({ }_{0} 2021\right.$ Yize Zuo et al. This is an open access article distributed under the Creative Commons Attribution License, which permits unrestricted use, distribution, and reproduction in any medium, provided the original work is properly cited.

\begin{abstract}
The state-of-the-art review of hybrid GFRP-concrete systems for bridge decks is presented in this study. Previous research on the experimental work, analytical modeling, and field application on hybrid GFRP-concrete deck systems are presented, along with a variety of deck systems are discussed. Then, seven typical types of connection technology between FRP and concrete are introduced and compared. Besides, the current progress on the performance of shear connections via beam tests, pushout tests, and pullout tests are probed, respectively. Finally, general conclusions are made, identifying the need for future research.
\end{abstract}

\section{Introduction}

Among all the bridge components, the bridge deck is the one that bears the most serious fatigue load. Also, the working state of decks directly affects the service life and performance of the bridge. Under long-term harsh environment, conventional bridge decks are prone to durability problems such as corrosion, cracking, and peeling [1-4], which bring huge hidden dangers and losses to infrastructure. Improvements in the durability of decks will result in lower life cycle costs and less frequent closures for replacements. Therefore, it is urgent to find some new materials and cost-effective solutions to build or replace conventional deck systems. In recent years, fiber reinforced polymer (FRP) composites have been widely used in the field of structural retrofit and new construction due to their material superiority. FRP composites have the following advantages [5-8] such as high strength-to-weight ratio, ease of site assembly, and high corrosion resistance as compared to other conventional materials such as steel, concrete, and timber as well as the fatigue resistance.

After nearly 30 years of development, FRP composites have been used in many forms in the field of bridges, such as FRP bridge deck, FRP composite beam, FRP double-webbed girder, and so on [9-11]. In these applications, FRP bridge decks can be mainly divided into FRP bar/grid reinforced concrete bridge decks, all-FRP bridge decks, and hybrid FRP-concrete bridge decks. In view of the disadvantages of FRP materials, such as low elastic modulus, brittle failure, anisotropy, and large initial investment, it is more feasible to rationally use FRP and steel or concrete or both to form hybrid bridge deck systems [12]. In these deck systems, not only can FRP structural members act as tensile reinforcements for the hardened concrete but also they serve as permanent formwork to reduce construction time and labor cost significantly. At the same time, FRP members can also avoid the durability problem of steel corrosion caused by the crack of the bottom concrete.

Currently, several scholars all over the world have designed and studied many types of hybrid FRP bridge decks with different section forms, and some applications have been made in small span bridges [13-15]. The 2014 review by Nelson et al. [16] further involved the development of several hybrid FRP-concrete deck systems up to 2012 but does not include the special study on the connection technology between GFRP and concrete. Besides, quite a few new developments have been achieved in the last 8 years, which are worthy of mentioning in a state-of-the-art survey. This study 
reviews the research status of hybrid GFRP-concrete decks and their connection performance, and several problems to be solved in future research are put forward.

\section{Hybrid GFRP-Concrete Deck Systems}

2.1. Experimental Testing and Validation. The concept of hybrid FRP and concrete deck system was proposed and has been studied since1990s [12, 17]. In 1994, Japanese researchers developed an FRP RC composite slab intending of life span and the shorting of the construction period [18]. As shown in Figure 1, the FRP flat plate (stiffened with I-typed ribs) was laid on the steel girder along the perpendicular direction of traffic and attached to the bottom of a conventionally designed RC slab. The fatigue and experimental results showed that the deck system had higher durability than conventional RC slabs $[19,20]$. However, the GFRP plate was utilized for durability consideration only and not assumed to contribute to the flexural property.

In 1998, Hall and Mottram [21] proposed a section of FRP panel with two T-upstands, on which concrete was poured to form hybrid FRP-concrete decks. The experimental study was conducted on the bonding behavior of the hybrid deck and the flexural behavior of the hybrid beam. The T-upstands of the FRP panel could bear tension and improve the bonding between the FRP and concrete. A linear elastic behavior was shown until the system failed from the experiment.

In 2002, Dieter et al. [22] developed a hybrid FRPconcrete deck system similar to that studied by Ldpez, and carried out a series of static and dynamic field tests. The deck layout is shown in Figure 2, and the FRP pultruded profiles with square tubes acted as stay-in-place (SIP) structural formwork and replaced tensile rebars at the bottom of the deck. The connection between FRP profiles and concrete was formed by coarse sand coating, and FRP grids were used to reinforce the upper part of the deck system. The key experimental results showed that accelerated flexural fatigue loading did not significantly decrease the stiffness of the reinforcement system. It was also found that a fully composite action between FRP and the concrete did not achieve.

In 2005, Cheng et al. [23, 24] developed a type of the modular hybrid FRP-concrete bridge deck system (Figure 3). The stiffened FRP panel acted both as SIP as well as flexural reinforcement. Experimental tests were conducted to study the static and fatigue behavior of the hybrid deck system according to AASHTO HS20. It was shown that the static performance met the design demand, and excellent fatigue response and very little deterioration were observed. This system satisfied the code requirements of both strength and serviceability.

In 2006, Keller et al. [25] conducted experimental research on a new type of hybrid FRP-concrete bridge deck system as shown in Figure 4. The lightweight concrete (LC) was sandwiched between the FRP with T-upstands and a thin layer of ultrahigh performance concrete (UHPC) in this bridge deck. Comparison tests were conducted with two types of LC and different LC/FRP interfaces. The decks could decrease the self-weight by $40 \%$ and increase the strength by $81 \%$, however, with brittle failure mode.

In 2008, Alnahhal and Aref developed a hybrid FRPconcrete system consisted of trapezoidal FRP cell units surrounded by an FRP outer shell and a thin layer of concrete placed in the compression zone (Figure 5(a)) [26]. The concrete was protected from air in enclosed space, slowing down the aging process. A series of loading tests such as nondestructive tests and destructive tests were conducted and confirmed that this system had excellent performance. Moreover, a series of service level flexural loading tests of decks on steel girders were carried out, within the shear studs used as a connection (Figure 5(b)) [27]. The deck system satisfied the AASHTO live load deflection limits but showed a less effective flange width.

In 2009, Hanus et al. investigated a structural FRP SIP form used to construct and reinforce a deck for a prototype military bridge system (Figure 6) [28]. For this application, the deck was subjected to combined bending and compressive longitudinal axial load because it also served as the top chord of the truss for the bridge system. The grids of FRP I-ribs and intersecting FRP reinforcement were epoxied to the FRP bottom panel, acting as stiffeners during construction and connectors.

In 2012, He et al. [29] proposed a cost-effective hybrid GFRP-concrete deck system as shown in Figure 7. The GFRP $\mathrm{T}$-shape ribs within rebars penetrating the reserved holes acted as the connectors and increased the stiffness of the SIP. This system was evaluated by sand filling and flexural static tests. The fatigue behavior of this deck system was also studied by Xin et al. [30]. The hybrid deck represented excellent fatigue performance even after 3.1 million repeated loading cycles.

Fam and Nelson [31] investigated corrugated GFRP plates as SIP forms with interlocking connections for concrete decks (Figure 8). The SIP form completely replaced the bottom layer of reinforcement; whereas, a top GFRP mesh was provided. The experiments focused on the performance of hybrid decks supported by concrete girders, and the cantilevered deck behavior was additionally studied. Very positive performance of this deck system was demonstrated.

In 2013, Nelson and Fam [32] proposed a new hybrid deck system that its GFRP SIP forms were flat plates with T-up ribs (Figure 9). Full-scale tests were conducted to evaluate the performance of hybrid decks with different connections between the deck and girders and the effect of anticrack GFRP bars on the top layer. In the same year, a series of $1: 2.75$ scale tests were also carried out to examine the critical parameters, namely, varying of the width of the deck specimens relative to their spans and varying interface bond condition, concrete strength, and loading location on the deck [33]. Furthermore, the durability of the deck under freeze-thaw (FT) cycles was evaluated. Eleven decks were subjected to three cracking load cycles before being saturated and subjected to up to $300 \mathrm{FT}$ cycles at $+5^{\circ} \mathrm{C}$ to $-18^{\circ} \mathrm{C}$ core temperatures [34]. All the studies are conducive to promoting the comprehension of the unique performance of the proposed hybrid deck system. In 2019, the postfire performance was investigated via bending tests after simulated-fire 


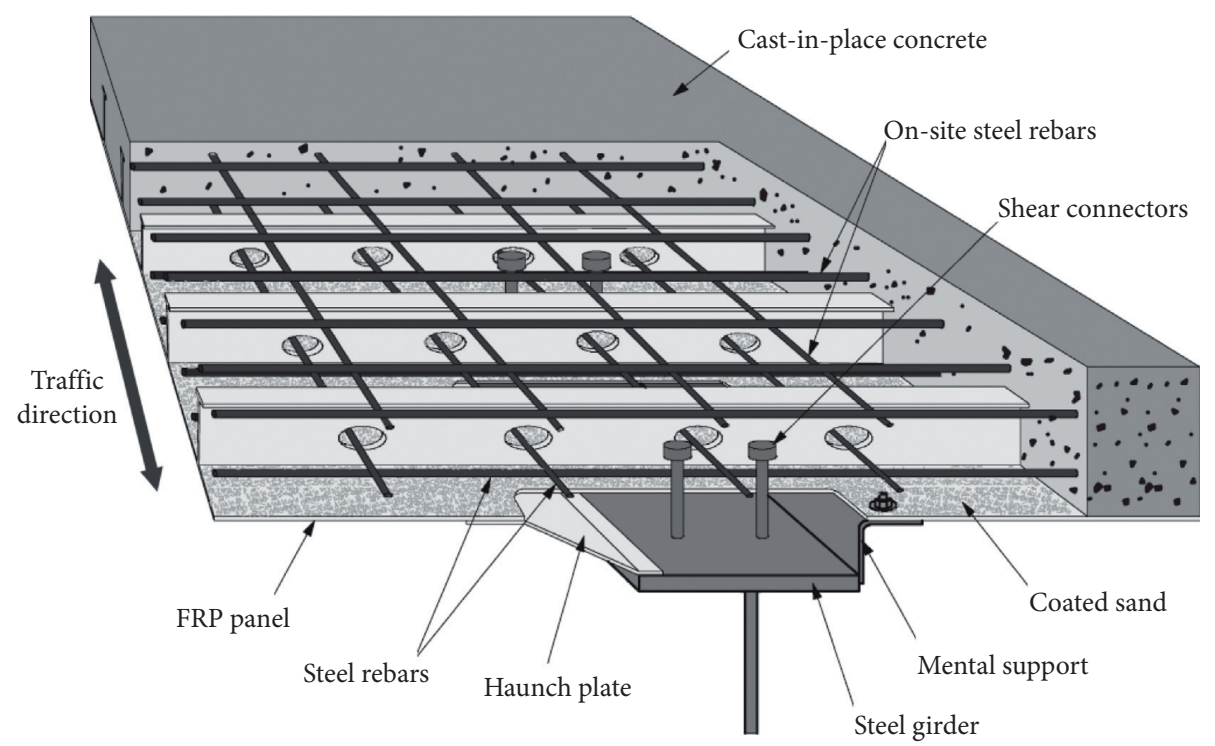

FIgURe 1: Schematic view of the hybrid deck studied by Japanese.

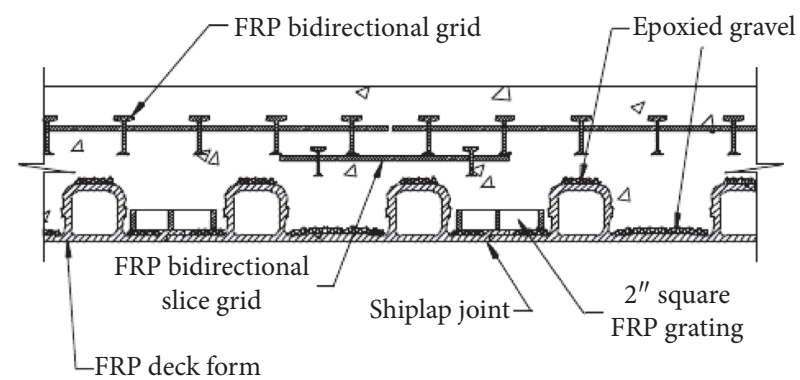

(a)

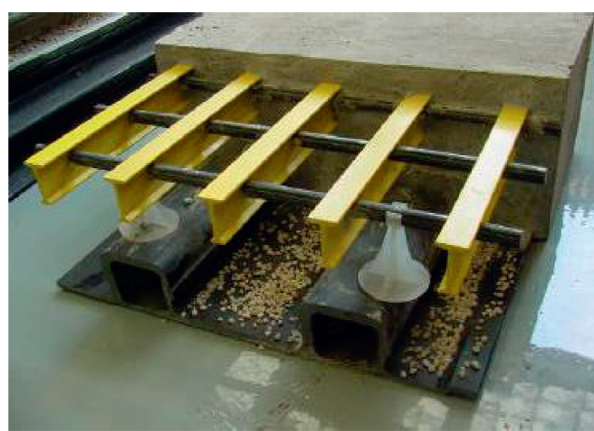

(b)

Figure 2: The layout of the hybrid deck studied by Dieter. (a) Cross-section layout. (b) Configuration detail.

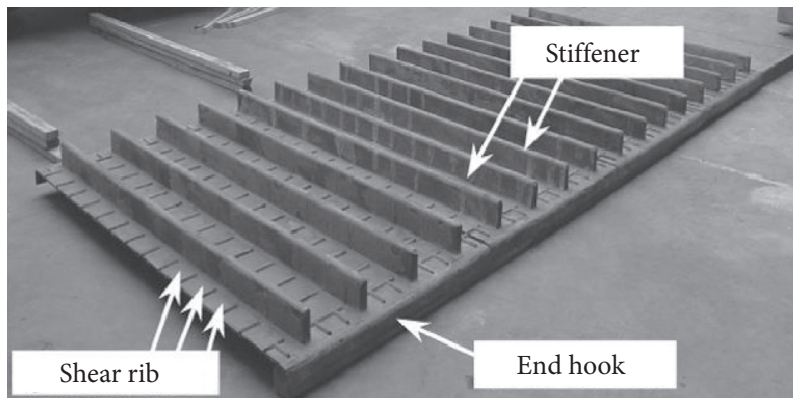

Figure 3: GFRP panel of the hybrid deck proposed by Cheng.

damage [35]. The fire damage was insufficient to reduce the ultimate load or change the failure mode of the deck.

In 2014, a newly lightweight hybrid deck system composed of pultruded trapezoidal GFRP tubes and the outer wrap was developed by Zhu and Lopez [36]. The red part in Figure 10 represents grouted with cells filled. Two-span tests of the deck system were performed to simulate a multigirder bridge configuration and to evaluate their structural behavior in both positive and negative bending regions. The results showed the hybrid deck met the AASHTO limit and performed well under service loads.

In 2016, Tuwair et al. developed a low-cost hybrid deck system consisting of trapezoidal-shaped GFRP pultruded plates and inner polyurethane foam (Figure 11) [37]. The proposed deck system exhibited good structural performance in terms of flexural stiffness, strength, shear stiffness, 


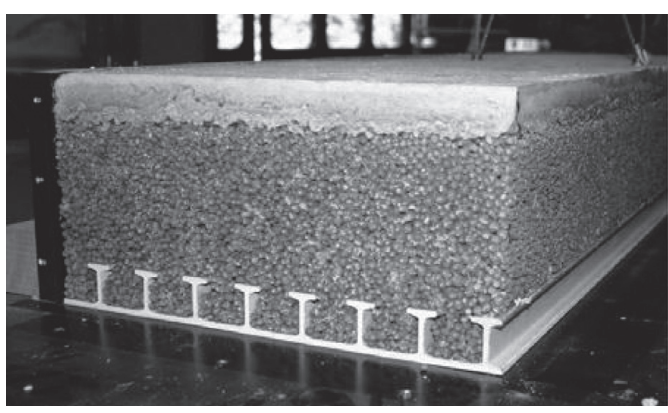

FIgURE 4: Hybrid FRP-LC deck proposed by Keller.

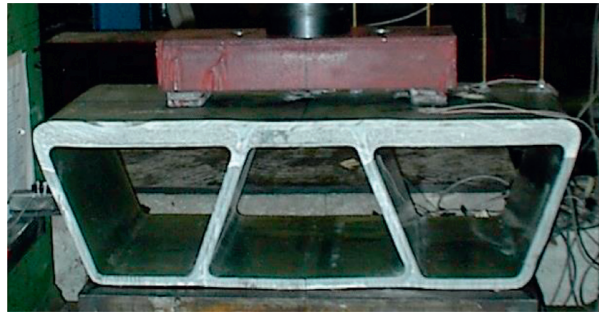

(a)

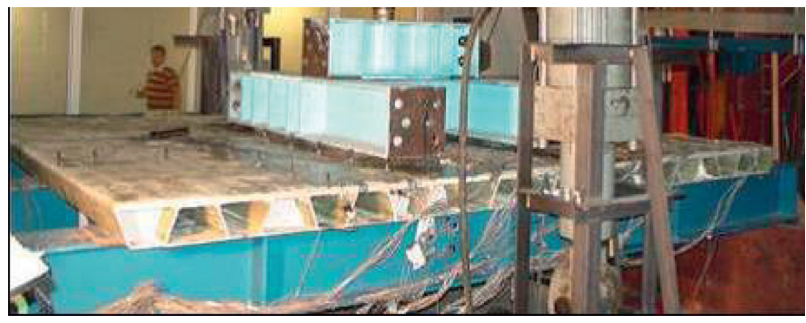

(b)

FIGURE 5: Hybrid deck system proposed by Alnahhal: (a) deck system; (b) deck on steel girders.

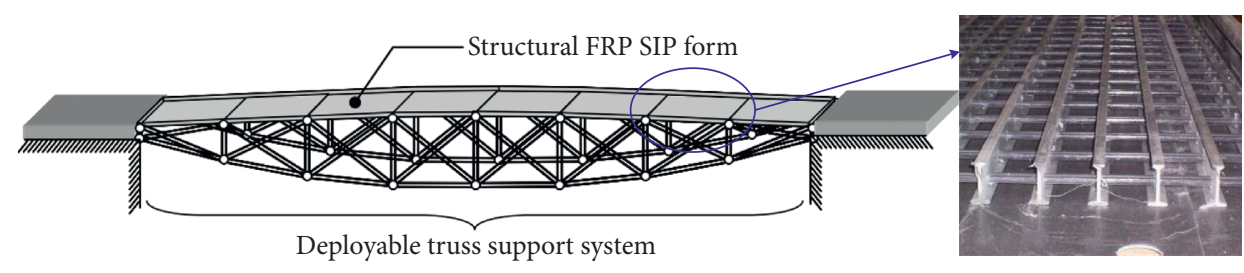

Figure 6: Construction stage of the deployable bridge.

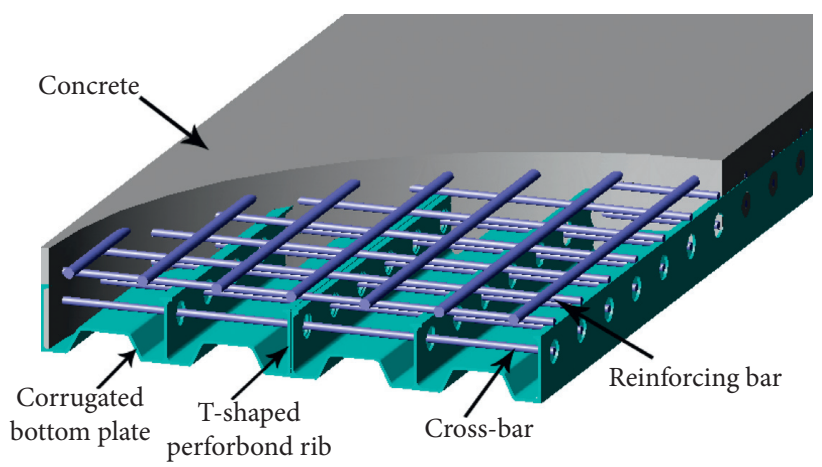

Figure 7: Hybrid deck system proposed by He.

and corrosion resistance through static and fatigue tests. In 2017, a new lightweight hybrid deck system of similar shape (Figure 12) was developed and investigated [38]. The deck system was composed of UHPC with high compressive strength and durability, CFRP sheets with high tensile strength, and GFRP profiles with shear resistance. The experimental results demonstrated that the target recommended strength demand for this deck was satisfied before failure.

Most recently, a novel hybrid GFRP-concrete deck system with composite $\mathrm{T}$-shaped perforated rib connectors was developed by Zuo et al. (Figure 13) [39, 40]. There were two other connection mechanisms except for the sandcoated GFRP plate surface: one was shear and uplift effects of 


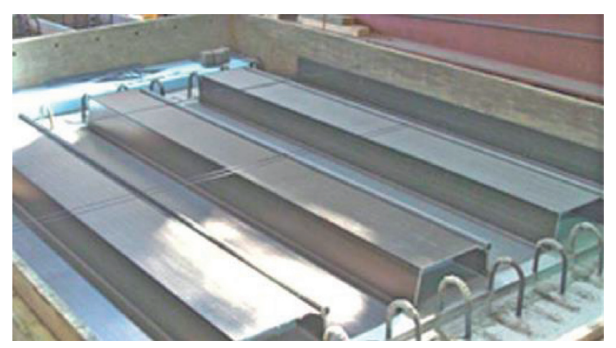

Figure 8: Top view of SIP form proposed by Fam.

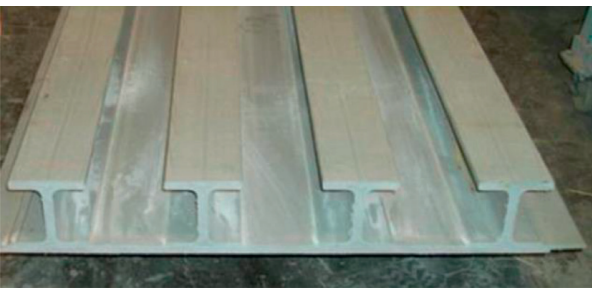

(a)

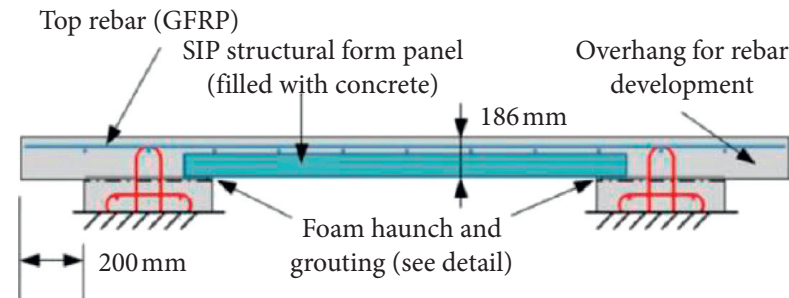

(b)

FIgURE 9: Hybrid deck system proposed by Nelson. (a) GFRP profiles. (b) Hybrid deck supported by precast concrete girders.

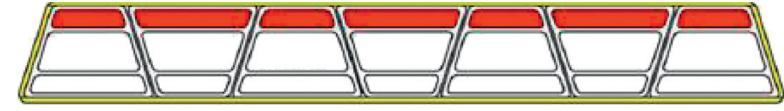

(a)

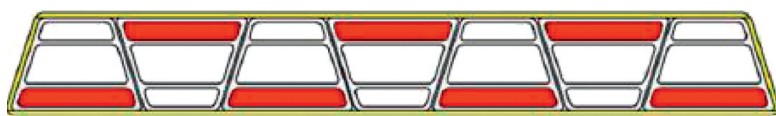

(b)

FIGURE 10: Hybrid deck system proposed by Zhu.

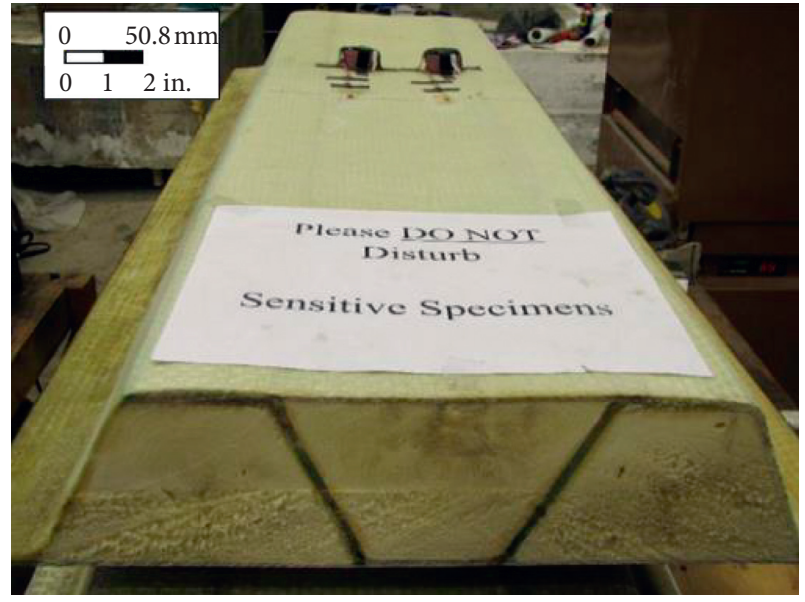

Figure 11: Hybrid deck system proposed by Tuwair.

GFRP T-shaped ribs, which was similar to headed studs and the other was formed by the penetrating bars through the holes in GFRP T-shaped perforated ribs. The behavior subjected to positive and negative moment was evaluated by

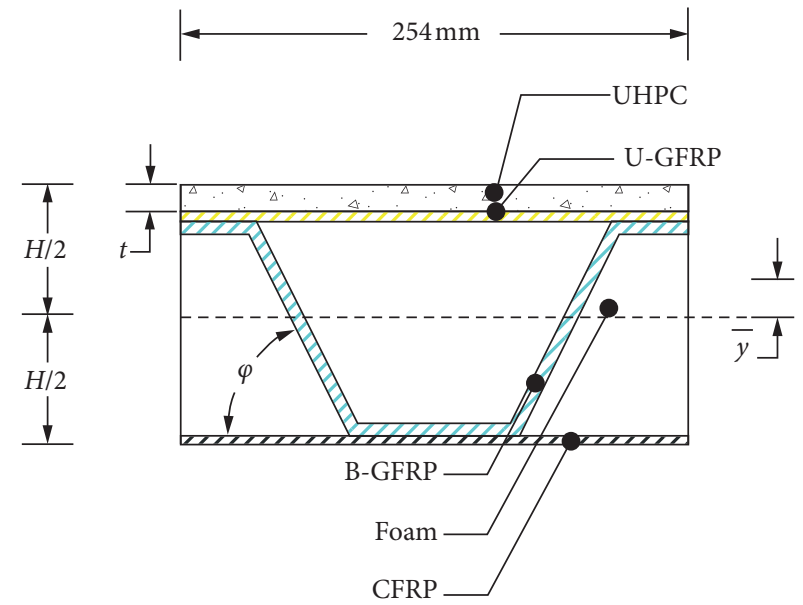

Figure 12: Hybrid deck system proposed by Ramahee.

static tests. Satisfactory performance was obtained from the test results; however, all of the hybrid deck specimens exhibited poor ductility subjected to the positive moment no matter which failure mode happened. 


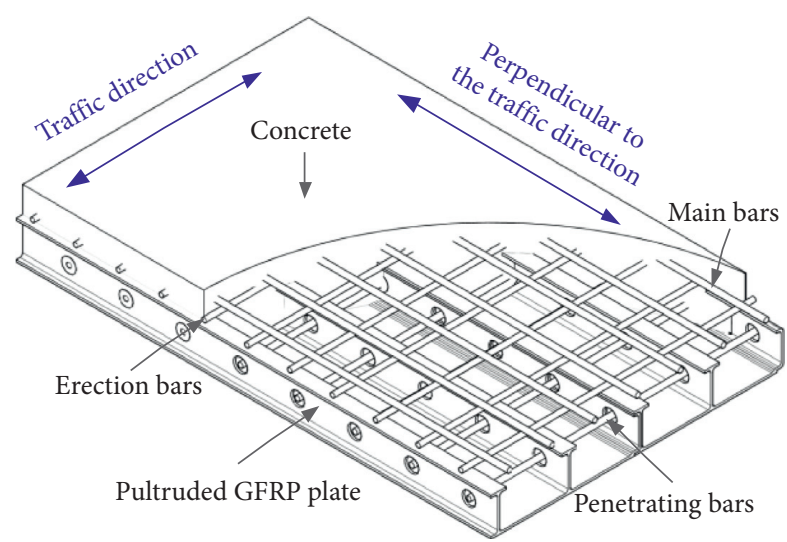

(a)

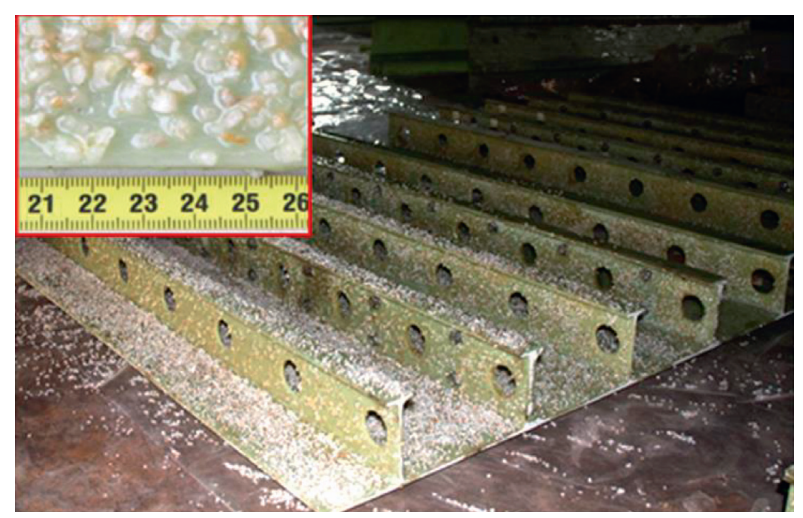

(b)

FIGURE 13: Hybrid deck system proposed by Zuo. (a) Schematic view. (b) The sand bonded GFRP plates.

2.2. Analytical Modeling. A large number of experimental works have been performed on hybrid GFRP-concrete decks. However, it was rather difficult to observe the inner failure mechanism during the loading process, and experimental works could not carry out abundant parametric studies to develop the design method. Therefore, the finite element (FE) analytical methods and the theoretical analysis are essential to comprehend the performance and the design approach of the hybrid deck system.

In 1989, Bakeri [41] built models based on the original concept of FRP as permanent formwork. Nonetheless, the analysis focused on the optimization of the laminate thickness in several inverse vault-like structures.

In 1998, more research on the system performance of the conventional pultruded FRP section was performed by Hall and Mottram [21]. A generalized analytical model for flexural behavior was developed based on an increment approach, predicting the nonlinear load-displacement curve and failure mode effectively. Nonetheless, this method was only applicable to unidirectional bending with some assumptions on end constraints, but these assumptions were not in accord with the actual boundary conditions of bridges.

In 2005, Cheng et al. [23] constructed a FE model to predict failure mechanisms and other behaviors of a hybrid FRP-concrete deck system, based on progressive laminates failure criteria. The analytical prediction compared well with full-scale test results. Later, parameterized studies were performed, and the FE model used was the first time to consider the interface characteristics between FRP and concrete [24].

In 2007, Oliva et al. [42] conducted numerical research on short-span hybrid FRP-concrete decks based on tests. Only a quarter model was built to save calculation costs. A damaged plasticity model was chosen to simulate the nonlinear behavior of the concrete, and the shell element was used for the FRP plates. The cohesive element in ABAQUS was adopted to simulate the interface between FRP plates and the concrete, and the constitutive relationship referred to the bonding stress-slip curve was obtained from tests. It is a satisfactory simulation method for the FRPconcrete interface.
In 2008, Alnahhal and Aref $[26,27]$ conducted FE analysis on the hybrid deck based on experimental research. Shell elements were used to simulate FRP pultruded profiles and solid elements for concrete. However, no slip between FRP and concrete was considered in the model.

In 2014, a robust analytical model for predicting full response and ultimate load of hybrid GFRP-concrete deck was proposed by Nelson and Fam [43]. It adopted the plate theory to establish surface deflections, while incorporating concrete nonlinearity, as well as the degree of the FRPconcrete bond. The model accounted for various boundary conditions at the edges of the deck in both directions, including both finite and infinite width in the direction of traffic, and either fixed or hinged conditions in the other direction, depending on the connection to the support girders. The model was validated against a large experimental database, and reasonable agreement was observed.

In 2015, Xin et al. [30] established a 3D FE model based on fatigue experimental works. Solid elements were adopted to simulate FRP pultruded profiles and concrete, which considered the nonlinearity and orthogonal anisotropy properties of FRP materials. The slip between FRP and concrete was simulated by hard contact in the normal direction, and penalty in the tangential direction was adopted for and the friction coefficient was chosen by the parametric study. In this way, the simulation exhibited good agreement with the experimental results. Later, similar modeling methods were used to compare the experimental results by Zuo et al. [40]. Moreover, there are some differences, in that the continuous shell element (SC8R) with lamina lay-up was used to simulate the nonlinear failure behavior of GFRP T-shaped perforated ribs. The laminate damage was considered based on Hashin's theory, and load transfer and failure mechanisms of GFRP perforated ribs were discussed.

In 2016, Noël and Fam [44] proposed two simple design equations for the ultimate load and stiffness of a hybrid deck system with FRP SIP, derived from the results of a comprehensive parametric study using a rigorous finite-difference computer model that was readily available. Stiffness was less accurately predicted; however, the model provided a reliable and accurate prediction of deflection. 
2.3. Applications in Practical Bridge Construction. In 1999, four types of hybrid FRP-concrete decks applied in Salem Avenue bridge in Ohio, USA, were evaluated [45], one of which is shown in Figure 14(a). FRP bars were used as upper reinforcement of the hybrid decks instead of steel bars. The high-temperature fatigue performance of this system was tested, and the results showed that the deck met the service load design criteria specified after one million fatigue cycling at a controlled high temperature of $49^{\circ} \mathrm{C}$. Later, these four types of hybrid decks were used in constructing one- and a half-spans of a five-span steel stringer supported concrete bridge [13].

In 2002, Erp et al. [14] conducted the static and dynamic behavior test on several small span test bridges consisted of FRP hybrid beams in Toowoomba, Australia (Figure 15). The hybrid beams tested were composed of FRP square tubes and the upper concrete. The tubes and concrete were glued with epoxy, and additional CFRP sheets were pasted on the bottom to improve the stiffness of the beam. High bearing capacity and good fatigue properties were validated by tests.

In 2003, the hybrid deck system studied in [22] was adopted in a two-span continuous beam bridge $(2 \times 32.7 \mathrm{~m})$ on US highway No.151 in Wisconsin (Figure 16). Berg et al. [15] evaluated the short-term material cost, labor time, and construction schedule and found that the hybrid FRPconcrete deck system reduced $57 \%$ the labor hours and increased $60 \%$ material cost compared with conventional decks. In the long run, the hybrid FRP-concrete bridge deck system was very economical.

\section{Connection Technology between FRP Profiles and Concrete}

3.1. Classification of Connection Technology. The interface between FRP profiles and the concrete should have reliable measures to ensure longitudinal shear transfer between the two materials, so that they can form hybrid bridge decks to work together. A variety of the FRP-concrete connections have been developed, mainly including the following six types:

(1) Adhesive [17]: this method is to apply an adhesive such as epoxy resin to the inner surface of FRP profiles and combine it with the pouring concrete on the contact surface. The connection quality is greatly influenced by the mechanical properties of the adhesive and the construction quality and stress transfer only in the contact surface. Moreover, brittle failure mode occurs within the low peeling capacity, and the aging property is also vulnerable.

(2) Sand coating [46, 47]: the roughened contact surface and coated sand develop shear connection performance close to perfect composition, as shown in Figure 17. The mechanism is to increase the surface roughness, expand the contact area, and enhance the bite force through using friction. However, the normal direction strength is usually less than 1.0 $\mathrm{MPa}$, which is an extreme weakness against the normal split.
(3) Mechanical interlocking [21, 22, 30, 47]: FRP profiles are combined with concrete by means of grids (Figure 18(a)), T-ribs (Figure 18(b)), and other mechanical connections. T-ribs and FRP bottom plates are integrated by integral pultruding or boding, and FRP profiles can be embedded into a depth in the concrete. This type not only can well resist the shear force of the contact surface but also the pullout force of bottom plates separating from the concrete. However, the shear capacity is relatively low.

(4) FRP shear keys [48] (Figure 19): it performs well in promoting the composite action, but their connection with the FRP girder is notably complicated which makes the construction difficult and materialconsuming.

(5) FRP dowels $[49,50]$ (Figure 20(a)) or steel bolts [51-53] (Figure 20(b)): similar to the stud connectors used in steel-concrete composite structures, FRP dowels or steel bolts are placed on the surface of GFRP profiles to resist the shear force. Their shear capacity is relatively high but prone to occur large slip, resulting in a weak composite effect. Besides, the inconvenience of installation should be considered.

(6) FRP perforated connectors $[29,30,39,40,54]$ (Figure 21): the action mechanism is similar to perfobond connectors in steel-concrete composite beams, which rely on the concrete wedge to resist the shear force. They usually have better pullout resist performance in the vertical direction of the junction surface. Preferably, steel bars or FRP bars can be perforated in the holes to improve the connection performance.

(7) Mixed type: this type is a combination of the above five methods, such as applying epoxy resins, coating sands, placing contact grids, and roughening on the inner surface of FRP profiles. According to the shape of FRP profiles, the advantages of various connection methods can be comprehensively utilized to better transfer the stress of contact surface between FRP profiles and the concrete, so that the two materials can be combined effectively.

3.2. Experimental Validation by the Beam Test. Deskovic et al. [17] proposed a kind of FRP-concrete composite beam in 1995. GFRP was used as a permanent formwork, which was coated with epoxy resin and then poured into the concrete. CFRP was glued to the bottom of GFRP box beams for reinforcement. In order to analyze the bonding properties of the interface, two bond techniques including bonding and additional steel bolts were investigated by flexural beam tests.

In 1999, six techniques to obtain shear transfer between GFRP profiles and the concrete were investigated by beam tests [55]. The six methods included (1) a mechanical bond using indents; (2) bonding by manual grit-blasting and epoxy adhesive; (3) mechanical bond using bolts; (4) 


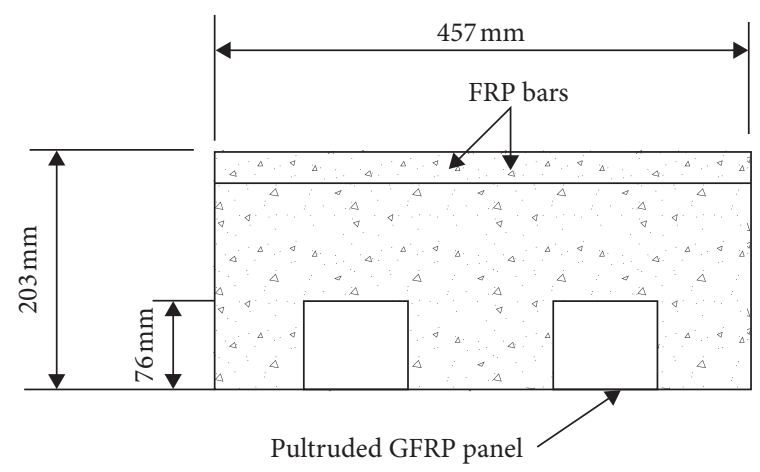

(a)

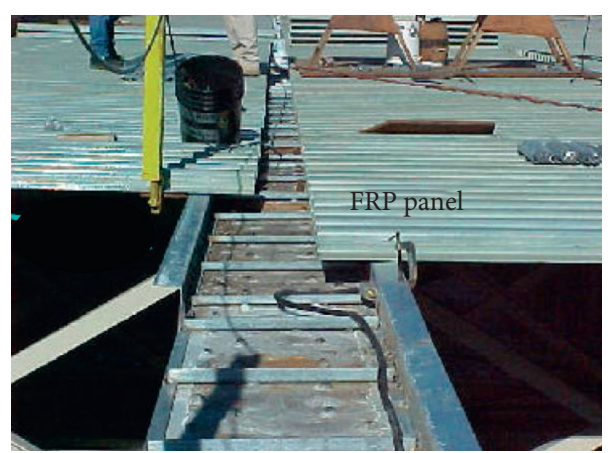

(b)

FIgure 14: The hybrid deck system applied by Ohio DOT. (a) One of hybrid deck systems. (b) FRP panels attached to steel girders.

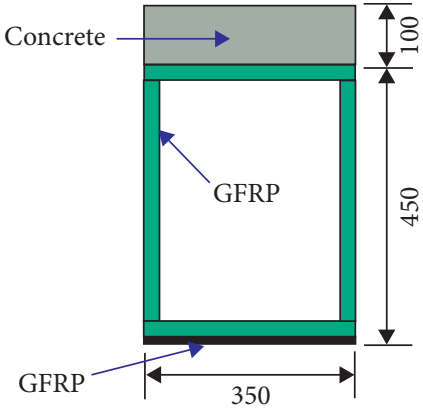

(a)

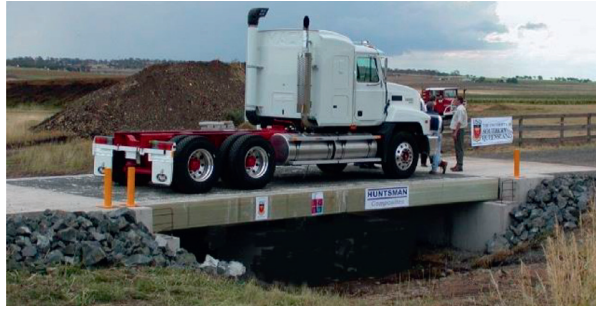

(b)

Figure 15: The hybrid beam system applied in Australia. (a) The cross-section of the hybrid beam (unit: mm). (b) Field testing of the bridge.

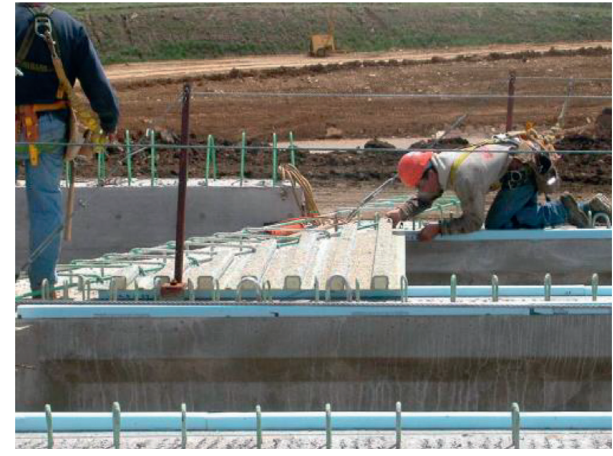

(a)

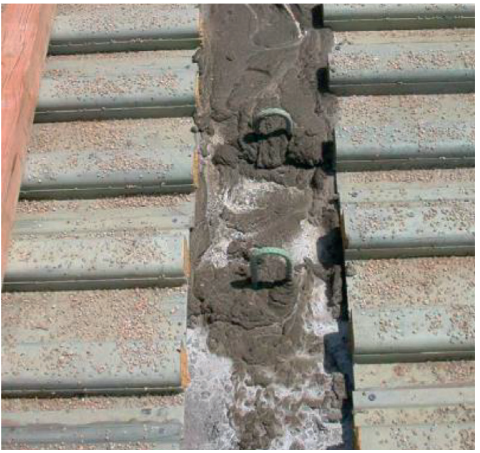

(b)

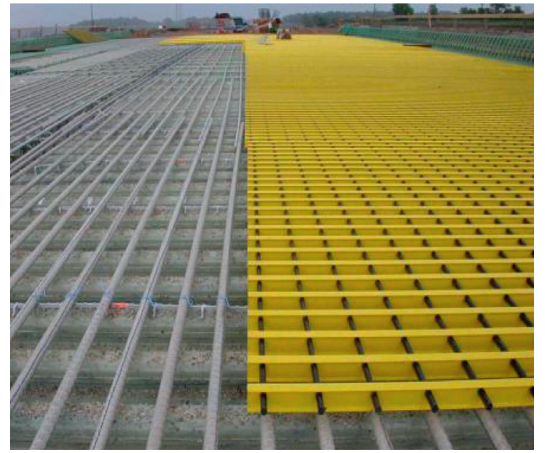

(c)

FIGURE 16: The hybrid beam system applied in Wisconsin, USA. (a) SIP FRP deck panel placement. (b) Roughened grout between SIP FRP deck panels. (c) FRP bars and grid placement.

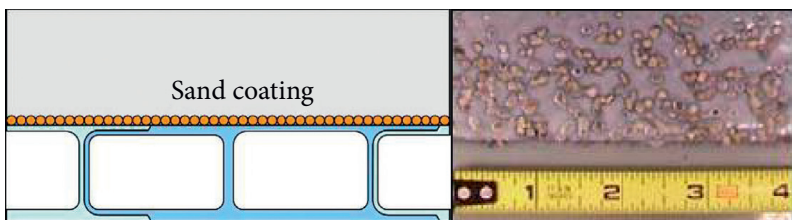

Figure 17: Overview sand coating connection type. 


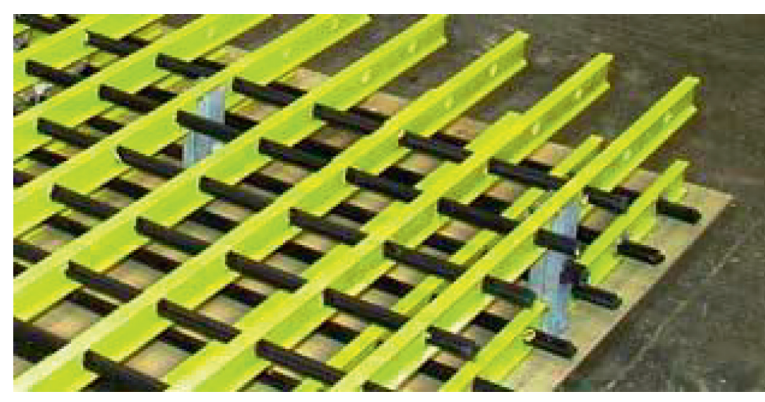

(a)

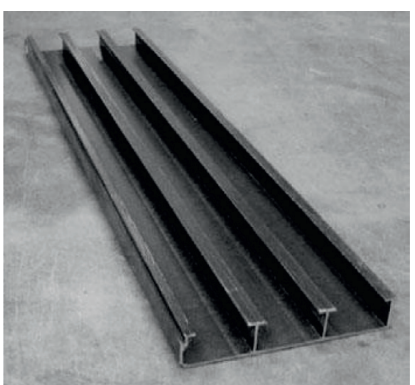

(b)

FIgURE 18: Mechanical interlocking connection type. (a) Grids connection. (b) T-ribs connection.

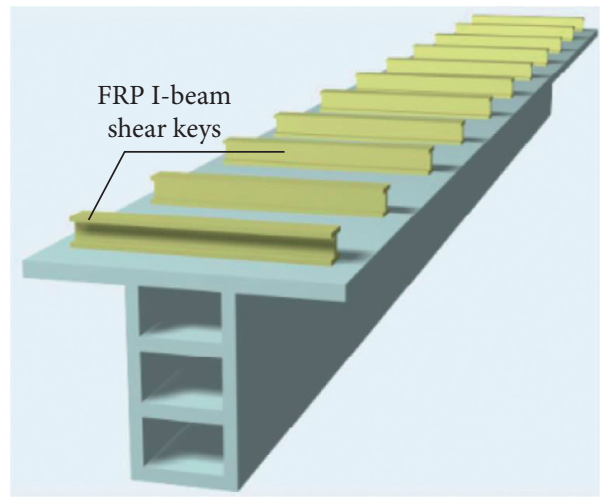

FIGURE 19: FRP shear keys type.

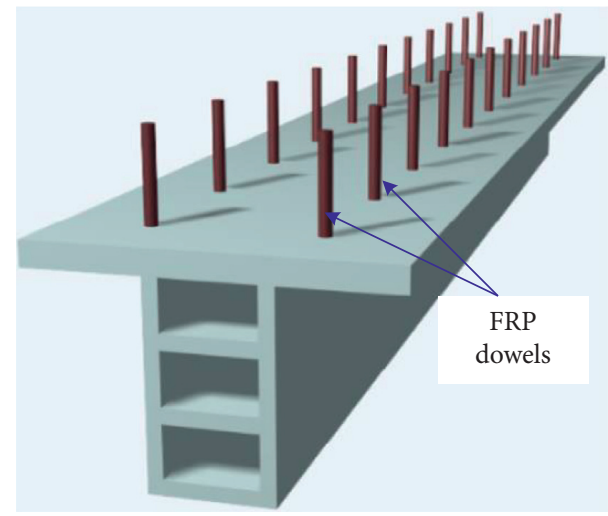

(a)

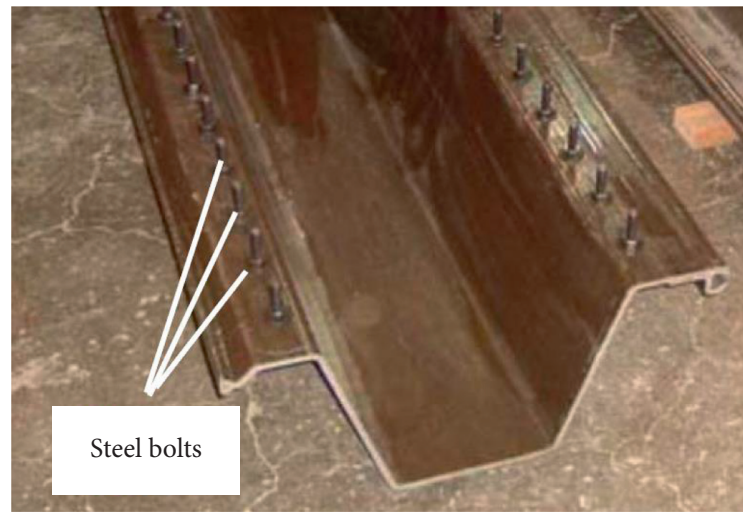

(b)

FIgURE 20: Overview sand coating connection type. (a) FRP dowels. (b) Steel bolts.

injecting adhesive into the preform gap between FRP plates and the concrete; (5) applying negative pressure at one end of the beam to fill the preform gap between the component parts; (6) and an epoxy adhesive suitable for bonding to fresh concrete. The investigated results showed that the best combination methods were the way of bonding by epoxy resin or injecting adhesive in the interface between the cured concrete and FRP profiles. In addition, the composite action could be guaranteed by the way of setting bolts, but the largest interface slip occurred, and the flexural rigidity was relatively low.

Six hybrid $\mathrm{T}$ beams made of new prepreg materials were investigated using duplex beam testing by Hulatt et al. [56]. As is shown in Figure 22, two designs of a $\mathrm{T}$ beam named type $A$ and type $B$ were analyzed. The difference between the two types was the number of layers of GFRP in the webs (two compared to four) and the way in which the beams were stiffened. In test results, no evidence of a failure of the 


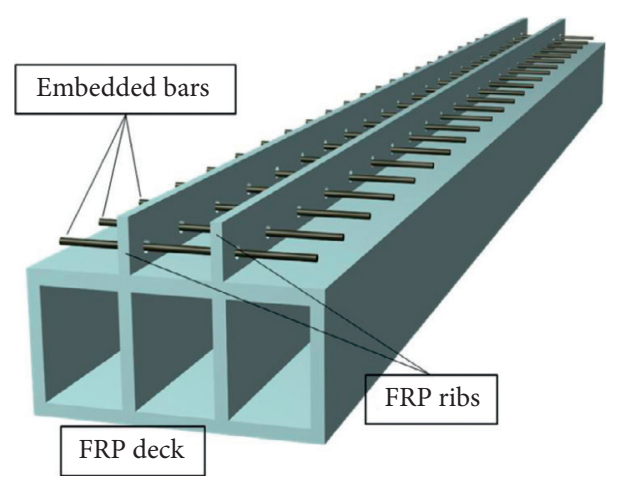

FIGURE 21: FRP perforated connectors for hybrid decks.

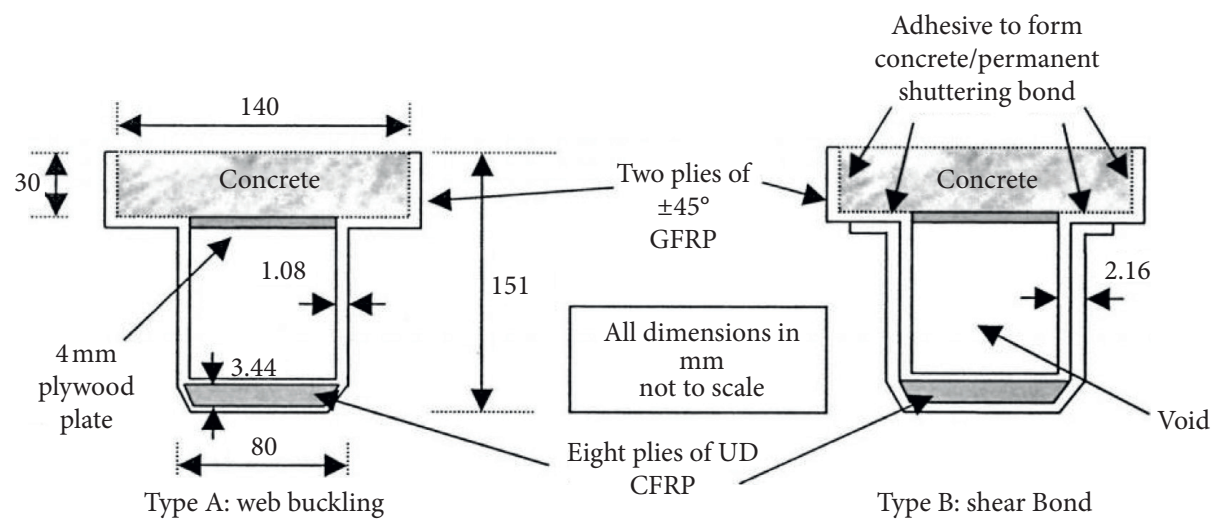

FIGURE 22: Completed cross-sections including basic dimensions.

interface between two materials was found in beam type B. The conclusion was obtained from this investigation: the epoxy resin could be brushed to the interface between FRP materials and the concrete to provide the necessary shear transfer and to ensure adequate composite action.

In 2004, Nordin and Täljsten [53] conducted the tests to investigate the behavior of hybrid FRP beams. There are three beams including two ways of interaction between the FRP profile and the concrete: steel bolts and epoxy adhesive, which is shown in Figure 23. For the beam in which concrete was cast with steel bolts (beam B), the failure mode was the concrete crushed and no visual failure was in the connection between the FRP and the concrete. This indicated that mechanically fastening the concrete with steel shear connectors was an efficient method. As for the beam in which precast concrete was epoxy bonded on the FRP (beam C), the concrete was shear off just above the bond area. The test results showed that the rigidity of beam $C$ was $20.9 \%$ higher than that of beam $\mathrm{B}$, while the strength was only $6 \%$ higher. Due to the concrete material properties of the two beams were not presented, what we could draw is that both the two kinds of connection could provide a very good composite action.

In 2014, two groups of 6 specimens were made for two types of shear connection of composite beams, namely, FRP small I-beam shear keys (Figure 19) and steel bolts connection (Figure 20(b)), and four-point bending tests were carried out [48]. The experimental results showed that the efficiency of the beam with steel bolts to transfer interface shear and the bearing capacity was better than that of the beam with FRP I-beam shear keys. The bonding performance of FRP small I-beam was obviously affected by the construction quality, which had great discreteness and weak antipeeling ability.

3.3. Experimental Validation by the Pushout Test. In 2011, Xue et al. [57] conducted two pushout tests to investigate the shear performance of FRP perfobond shear connectors. Failure modes, load-slip behavior, and shear capacity load were studied. Shear failure of FRP ribs occurred, while no damage was observed on the concrete dowels and the GFRP bars penetrated in the holes. The FRP perfobond connectors showed relatively high shear capacity and could be applied to the FRP-concrete composite deck.

In 2013, the connection behavior between the FRP deck and steel girders was investigated by Chou via conducting pushout tests on four specimens with the FRP deck (Figure 24) [58]. The FRP deck was grouted to the steel girder using shear studs, which were welded on top of the girder at locations corresponding to every closed cell of the deck. The test results revealed that the ultimate shear strength of the FRP deck-to-girder connection was overestimated per AASHTO LRFD bridge design specifications (2004) due to gout cell flexibility and bedding layer damage. 


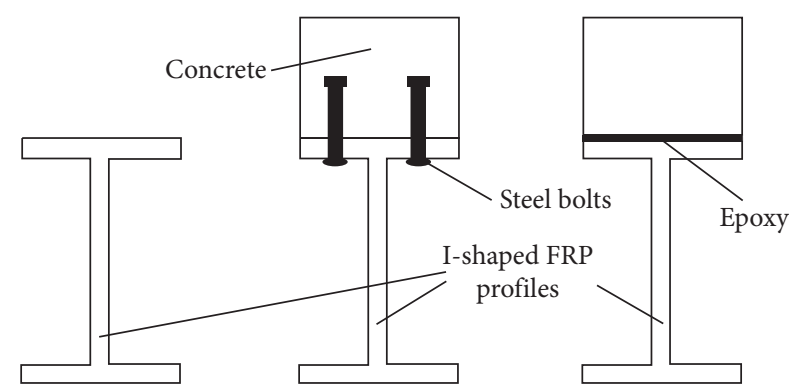

FIGURE 23: Connection technologies between FRP profiles and concrete studied by Nordin.

In 2016, Zou et al. [59] conducted tests on four pushout specimens that adopted perforated FRP ribs (PFRs) and steel bolts as connection methods, respectively. The PFRs were epoxy bonded on pultruded FRP I-profiles. Based on the experimental and theoretical results, calculation equations are for shear capacity and slip modulus of PFRs. Test results showed the shear capacity of PFRs was 2.5 times that of steel bolts, while the slip modulus of PFRs was 10 times that of steel bolts. Theoretical analysis indicated that the slip modulus of PFRs increased proportionally with the area of the concrete wedge and the thickness of the perforated plate. Besides, the shear failure of perforated FRP plates preceded the failure of the concrete wedge, which controlled the design of PFRs. The shear performance of PFRs was obviously different from that of steel perfobond connectors.

In 2017, the bond behavior of GFRP I-section embedded in concrete was studied using the pushout test by Yuan and Hadi [60]. The main parameters investigated were bond length $(300-400 \mathrm{~mm})$, transverse stirrups, and sand coating. The results showed that the ultimate bond stress could be improved by a loner bond length and sand coating. However, the stirrups affected the vibration of concrete, causing weak bond stress.

In the same year, 27 GFRP-concrete composite desk connection specimens with four different kinds of bonding patterns were tested via pushout experiments by Guo et al. [61]. These patterns included epoxy resin wet bonding, rough sand-coated bonding, GFRP shear key, sand coated, and shear key mixed type. The bonding strength of all bonding patterns was high and could be potentially used as the shear resistance countermeasures. The bonding strength of the interface of the GFRP-concrete composite deck was related to the surface roughness condition, bonding behavior of cohesive, arrangement pattern of the shear connectors, and concrete strength. Besides, although mechanical interlocking type could increase the bonding strength of the interface, its effect was limited, so it was not recommended to use it alone.

Five groups of pushout specimens with GFRP shear connectors were fabricated and tested by Huang et al. [62]. The effect of three variables named GFRP rib shapes, the presence of holes, and the existence of transverse rebars was investigated, as shown in Figure 25. Some conclusions were obtained: (1) due to the increase of the shear area of GFRP connectors, the shear strength and ductility of T-type rib shear connectors were greater than those of flat plate shear connectors; (2) the concrete dowels in the holes provided continuous shear resistance after interface slippage occurred. Holes significantly improved shear resistance and ductility; (3) transverse rebars significantly affected shear resistance behavior. Splitting failure of concrete slabs occurred in specimens without transverse rebar, while GFRP connectors fractured in the root in specimens without transverse rebar; (4) the shear resistance and ductility of GFRP shear connectors decreased as the number of transverse rebars increased because the shear area of GFRP shear connectors decrease as the number of holes increased. Besides, empirical shear resistance equations for GFRP shear connectors were also presented.

In 2018, Zou et al. proposed an assembly FRP-concrete hybrid beams/decks (Figure 26) which consisted of FRP girders, FRP shear keys, bolts connectors, and FRP SIP forms [63]. The slip modulus and shear capacity of FRP shear keys, SIP, and their combination were investigated through thirteen pushout specimens. There are four groups in total with different variables. Group I was comprised of 2 normal strength steel bolt specimens and 2 high-strength steel bolt specimens. Group II connected the FRP girder and concrete with different cross-sections of shear keys (L, C, and $\mathrm{H}$ typed, respectively). Group III combined bonded $\mathrm{H}$-typed shear keys and SIP, while group IV combined steel bolts and SIP. A total of five different failure modes were observed. The results revealed that FRP shear keys formed full interactions with the same level of shear capacity as steel bolts and about ten times the slip modulus compared with steel bolts. In addition, the cross-section of the FRP shear keys was not a significant parameter because all of the shapes failed at the peeling of the FRP flange surface, and no damages were found in the shear keys.

In 2019, Gong et al. conducted an experimental investigation of the natural bonding strength between FRP profiles and in situ cast concrete [64]. Four pushout test specimens were carried out as same as the part of [63], in which two specimens were equipped with steel bolts as the interfacial connection, and the other two were equipped with the SIP form and steel bolts together. The failure mode for all specimens was the shear fracture of steel bolts, and results revealed that the use of SIP forms could slightly improve the ultimate shear capacity. Furthermore, two hybrid FRPconcrete beams with a complicated SIP form were tested. A conclusion could be obtained that natural bonding between the FRP SIP form and the concrete could provide the full composite action in the initial flexural stage, the releasing the natural bonding effect formed the plateau in the second stage, and steel bolts provided the partial composite action in the third stage.

In 2020, Di et al. conducted pushout tests involving 11 specimens to investigate the influence of different types of connections between GFRP and concrete [65]. Three groups were divided having high-strength bolts, T-typed FRP perforated plate, and slot-typed FRP perforated plate connections. The test results revealed that the failure mode of bolts specimens was brittle failure, and the perforated plate was ductile failure. Besides, the shear capacities of single perforated plates were higher than that of single bolts. The 


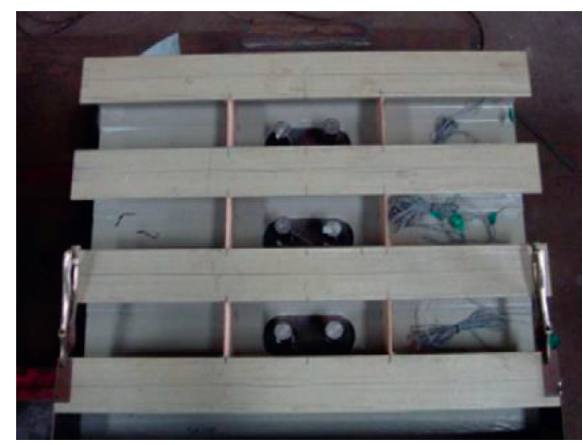

(a)

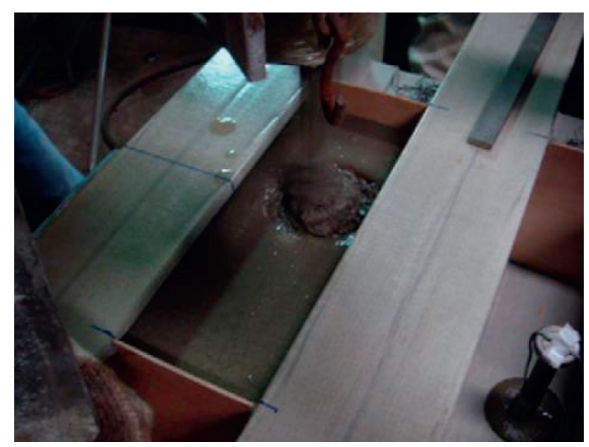

(b)

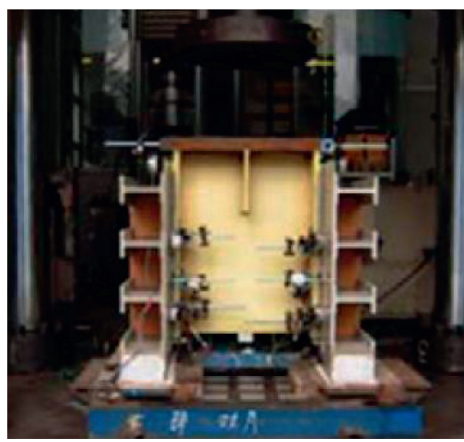

(c)

FIGURE 24: FRP deck-to-steel girders connection push-out test conducted by Cho. (a) FRP deck fabrication. (b) Grout pouring. (c) Test setup.

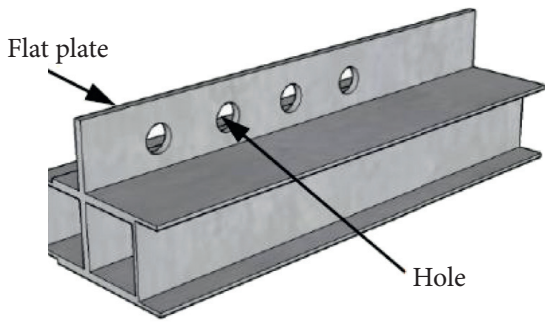

(a)

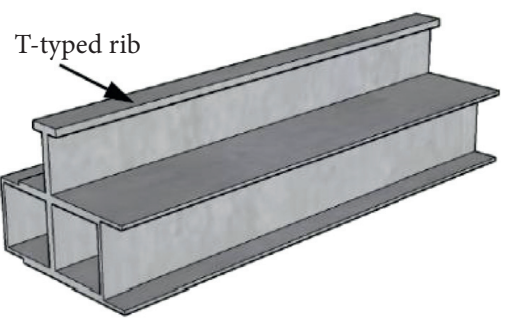

(b)

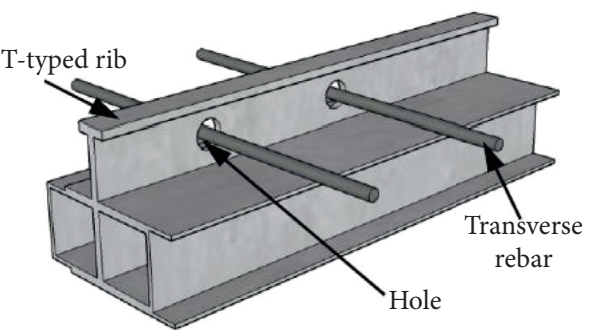

(d)

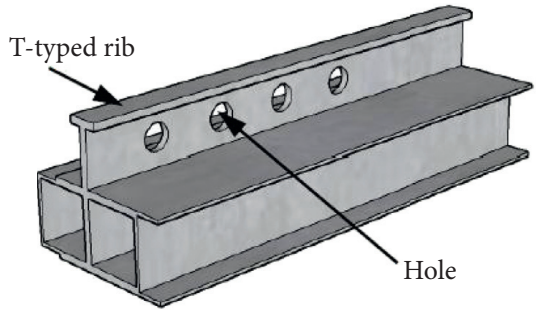

(c)

FIGURE 25: Configuration of GFRP shear connectors investigated by Huang.

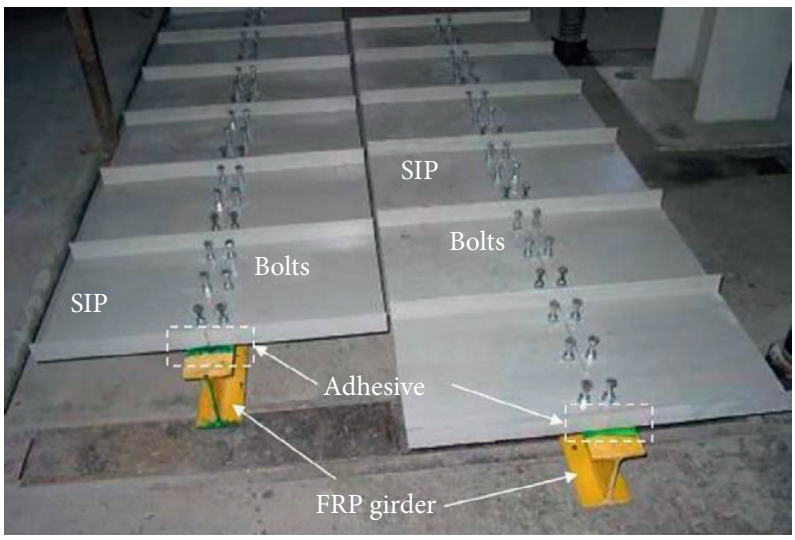

FIGURE 26: FRP-concrete hybrid beams proposed before casting. 


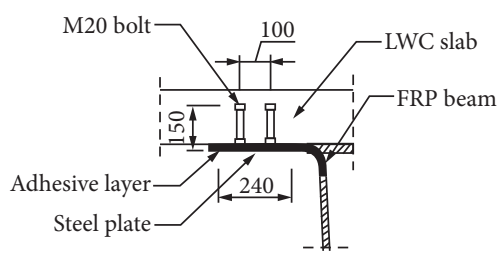

(a)

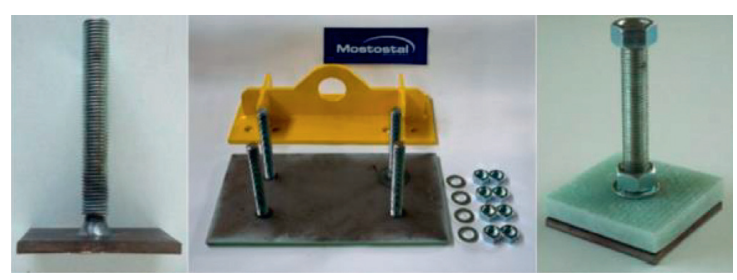

(b)

Figure 27: Concept and elements of the novel shear connection system.

transverse rebar could increase the capacity and ductility in the plastic stage for perforated plates. In general, the T-shaped and slotted perforated plates exhibited better antisliding ability and a higher shear capacity than bolts connectors for hybrid GFRP-concrete decks.

In 2020, Rajchel et al. developed a novel shear connection system for hybrid girders that consist of FRP beams and concrete slabs [66]. As shown in Figure 27, the connector was comprised of a steel plate and welded bolts attached to the FRP beam's top flange by adhesive bonding and with a preset torque of nuts. Three static pushout tests and fatigue tests were carried out to evaluate the shear behavior of the proposed connectors. Bolt shank fracture was the only failure mode in the static tests, while the weld toe fracture in welds joining shear bolts to steel plate was the failure mode in fatigue. Moreover, the ductility, static, and fatigue strength of this connector were better than those of typical shear studs used for composite steel-concrete beams. This is the first time that the fatigue performance of connection systems between FRP and concrete was studied by pushout tests.

3.4. Experimental Validation by the Pullout Test. In 2005, the wet-bond behavior of FRP laminates to the fresh concrete was investigated by JSCE pullout tests and compared to conventional dry-bond using dry concrete [67]. The test results showed that the load-displacement curves, the strain distributions in FRP, and the interfacial fracture energy of dry-bond and wet bond specimens were closely comparable. Epoxy adhesive wet-bonding technology provided an economic alternative to form FRP-concrete composite structures.

In 2007, Wang et al. [68] conducted a series of single shear tests to investigate the bond behavior of FRP plates with shear key and concrete. The test results indicated that the average bond strength between FRP plates and concrete was significantly affected by the length of shear key, the interface reinforced by appending coated sand and the strength of concrete, while the change of the height and width of shear bond had no obvious effect on the bond strength.

In 2010, Cho et al. [69] examined the effect of aggregate size and density on the shear bond characteristics of the coarse sand coated interface between stay-in-place FRP formwork and concrete via pullout tests of double-lap joints. The test variables were aggregate and density. The results showed that the shear bond performance improved with smaller aggregate size and larger distribution density. Furthermore, the local shear bond stress-slip model of the coarse sand coating was derived through an optimization process.

In 2012, Cho et al. [54] carried out a series of pullout tests on FRP perforated plate connectors to study their shear behavior, and the test parameters were the size and numbers of rib holes. The two failure modes were observed as shown in Figure 28. The test results revealed that the shear capacity of the concrete dowel was in linear proportion to the area of the holes, while it was in nonlinear relation to the number of holes with a slight loss for a larger number of holes, due to the sequential failure of the rib holes. At last, based on the regression analysis of the load-slip curve of single-hole rib, the constitutive equation of the discrete spring model representing the concrete dowel including postfailure frictional effects was derived, adopting the diameter of the rib hole as the parameter.

In 2016, to evaluate the GFRP connectors for connecting the outer self-compacting concrete, Lameiras et al. performed pullout tests with specimens as representative of the developed sandwich panel [70]. The variables consisted of different GFRP laminates, types of concrete, and different geometries for the connector (without holes, with 3 holes and with 4 holes). The results showed that GFRP connectors with holes increased the shear capacity of connections, and the failure modes depended on the type of concrete, the type, and the thickness of GFRP laminates.

In 2019, Xiong et al. conducted a series of 26 pullout tests to evaluate the shear behavior of GFRP perforated connectors embedded in concrete (Figure 29) [71]. The experimental variables included the effects of plate thickness, plate hole's radius, and penetrating bars. Concrete dowel failure and GFRP shear-out failure were the two main failure modes. GFRP failure occurred in specimens with a thin plate, and ultimate strength was mainly affected by the hole's radius. The specimens with concrete dowel failure presented were more ductile than the specimens with GFRP shear-out failure. The shear stiffness of GFRP perforated connectors was determined based on load-slip curves. Moreover, with a collection of other test data as a complement, the equations 


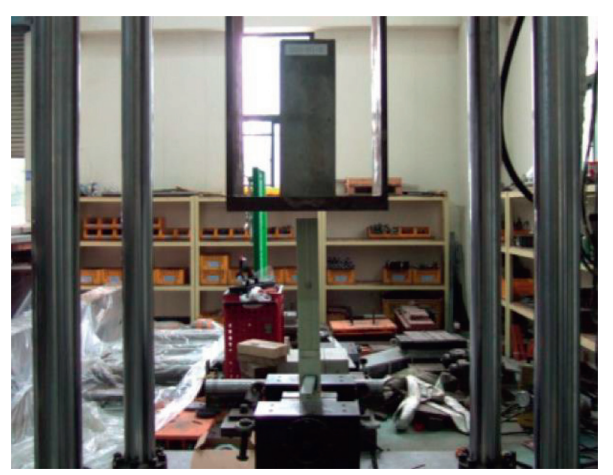

(a)

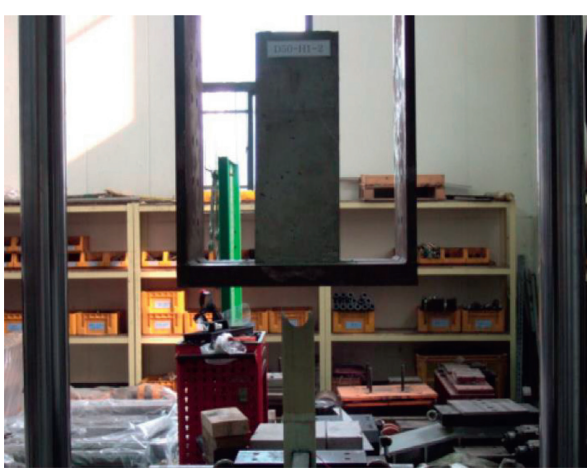

(b)

FIgURE 28: Two different failure modes in the pullout test: (a) concrete failure; (b) FRP rapture.
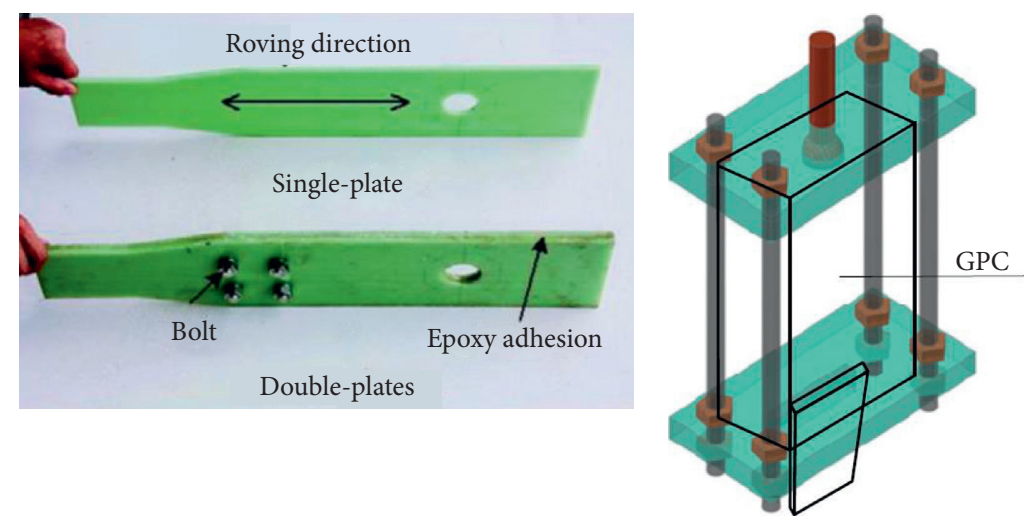

(a)

(b)

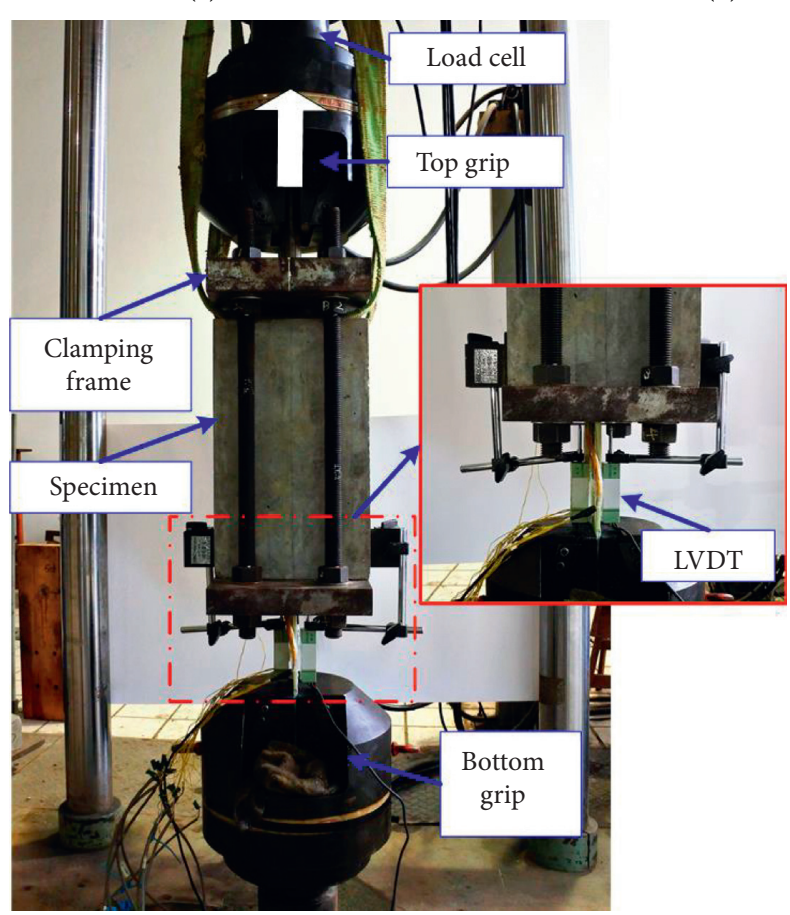

(c)

Figure 29: Plates arrangements and test setup studied by Xiong. (a) Plate arrangements. (b) Clamping frame. (c) Test rig. 
to predict the shear strength incorporating the stress concentration in the GFRP plate and the restraint effect of penetrating rebar were proposed and verified. In particular, a critical thickness of the GFRP plate was proposed according to the strength equations to guarantee the rational strength and ductility of GFRP perforated connectors.

\section{Conclusion and Further Studies}

The current reviewing focus has been given to the development of several typical hybrid decks in this study. Conclusions from research efforts are that hybrid FRP-concrete deck systems have a very broad application prospect in bridge engineering, but there are still several aspects to be further studied as follows.

(1) The hybrid FRP-concrete bridge deck system contains multiple systems of connections, such as the connection between different FRP components, the connection between FRP and concrete, and the connection between hybrid decks and support system. The connection property of the whole deck system is different from various connection methods. Studying and selecting the best connection method and clarifying its failure mechanism is still one of the key problems in promoting and applying the hybrid GFRP-concrete deck system. Moreover, the static design method, the fatigue failure mechanism, and the design method of connection methods need to be further studied.

(2) Most of the hybrid GFRP-concrete deck systems tend to fail in shear modes and show poor ductility, which governs the structural design. Effective measures and more rational hybrid deck systems combing FRP and ultrahigh performance materials should be developed to further improve the flexural behavior.

(3) More future studies should address the performance of the system under creep effects, cyclic fatigue loading, and freeze-thaw cycles. Besides, the effects of UV exposure, temperature, humidity, and concrete alkalinity of the hybrid FRP-concrete deck system are not well understood, even though FRP materials have excellent corrosion resistance. Additional assessments on the actual long-term performance of the hybrid deck system should be conducted by field project tests.

(4) Thus far, the existing design methods for FRP composite structures are not rough, and there is no specific design code for the hybrid FRP-concrete bridge deck system. Efforts need to be made to synthesize current design methods in order to produce concise design guidelines for hybrid FRPconcrete deck systems. Such a guide should encompass all the commercially available systems.

(5) In recent 15 years, there are almost no practical bridges using the hybrid GFRP-concrete deck system. More pilot bridge applications are needed to understand the viability and detail of hybrid GFRPconcrete deck systems.

\section{Conflicts of Interest}

The authors declare that they have no conflicts of interest.

\section{References}

[1] Z. Zhang, Q. Wang, H. Chen, and Y. Zhou, "Influence of the initial moist curing time on the sulfate attack resistance of concretes with different binders," Construction and Building Materials, vol. 144, pp. 541-551, 2017.

[2] Q. Wang, J. J. Feng, and P. Y. Yan, "An explanation for the negative effect of elevated temperature at early ages on the late-age strength of concrete," Journal of Materials Science, vol. 46, no. 22, pp. 7279-7288, 2011.

[3] L. Wang, T. He, Y. Zhou et al., "The influence of fiber type and length on the cracking resistance, durability and pore structure of face slab concrete," Construction and Building Materials, vol. 282, Article ID 122706, 2021.

[4] L. Wang, R. Luo, W. Zhang, M. Jin, and S. Tang, "Effects of fineness and content of phosphorus slag on cement hydration, permeability, pore structure and fractal dimension of concrete," Fractals, vol. 29, no. 2, Article ID 2140004, 2021.

[5] E. Barbero, Introduction to Composite Materials Design, CRC Press, Boca Raton, FL, USA, 2011.

[6] Y. Zhang, A. Mosallam, Y. Liu, Y. Sun, H. Xin, and J. He, "Assessment of flexural behavior of pultruded GFRP laminates for bridge deck applications," Advances in Materials Science and Engineering, vol. 2019, Article ID 6751636, 11 pages, 2019.

[7] H. Xin, A. Mosallam, Y. Liu, C. Wang, and Y. Zhang, "Analytical and experimental evaluation of flexural behavior of FRP pultruded composite profiles for bridge deck structural design," Construction and Building Materials, vol. 150, pp. 123-149, 2017.

[8] H. Xin, Y. Liu, and A. Du, "Thermal analysis on composite girder with hybrid GFRP-concrete deck," Steel and Composite Structures, vol. 19, no. 5, pp. 1221-1236, 2015.

[9] L. Bank, Composites for Construction: Structural Design with FRP Materials, Wiley, Hoboken, NJ, USA, 2006.

[10] C. E. Bakis, L. C. Bank, V. L. Brown et al., "Fiber-reinforced polymer composites for construction-state-of-the-art review," Journal of Composites for Construction, vol. 6, no. 2, pp. 73-87, 2002.

[11] A. Mosallam, A. Bayraktar, M. Elmikawi, S. Pul, and S. Adanur, "Polymer composites in construction: an overview," SOJ Materials Science \& Engineering, vol. 2, no. 1, p. 25, 2015.

[12] P. Bakeri and S. Sunder, "Concepts for hybrid FRP bridge deck system, "Serviceability and durability of construction materials," in Proceedings of the First Materials Engineering Congress, vol. 2, pp. 1006-1015, ASCE, Denver, CO, USA, August 1990.

[13] R. M. W. Reising, B. M. Shahrooz, V. J. Hunt et al., "Performance of five-span steel bridge with fiber-reinforced polymer composite deck panels," Transportation Research Record: Journal of the Transportation Research Board, vol. 1770, no. 1, pp. 113-123, 2001.

[14] G. Erp, T. Heldt, L. McCormick, D. Carter, and C. Tranberg, "Development of an innovative fibre composite deck unit bridge," in Proceedings of the IABSE Symposium, Melbourne, Australia, September 2002. 
[15] A. C. Berg, L. C. Bank, M. G. Oliva, and J. S. Russell, "Construction and cost analysis of an FRP reinforced concrete bridge deck," Construction and Building Materials, vol. 20, no. 8, pp. 515-526, 2006.

[16] M. Nelson, A. Fam, J. Busel et al., "FRP stay-in-place structural forms for concrete bridge decks: a state-of-the-art review," ACI Structural Journal, vol. 111, no. 5, pp. 1069-1080, 2014.

[17] N. Deskovic, T. C. Triantafillou, and U. Meier, "Innovative design of FRP combined with concrete: short-term behavior," Journal of Structural Engineering, vol. 121, no. 7, pp. 10691078, 1995.

[18] S. Ishizaki, S. Matsui, and K. Kubo, "A study on FRP permanent form for reinforced concrete slabs," Technology Reports of the Osaka University, vol. 44, pp. 295-307, 1994.

[19] S. Matsui, S. Ishizaki, and K. Kubo, "A study on static strength and durabilities of RC slabs stiffened by FRP permanent formwork," Collected Papers of Structural Engineering. JSCE, vol. 40A, pp. 1413-1424, 1994, in Japanese.

[20] K. Kubo and N. Hayashi, "Field loading tests for decade-old FRP-RC composite slab (Matsukubo bridge)," Miyaji Technical Report, Tokyo, Japan, 2009, in Japanese.

[21] J. E. Hall and J. T. Mottram, "Combined FRP reinforcement and permanent formwork for concrete members," Journal of Composites for Construction, vol. 2, no. 2, pp. 78-86, 1998.

[22] D. A. Dieter, J. S. Dietsche, L. C. Bank, M. G. Oliva, and J. S. Russell, "Concrete bridge decks constructed with fiberreinforced polymer stay-in-place forms and grid reinforcing," Transportation Research Record: Journal of the Transportation Research Board, vol. 1814, no. 1, pp. 219-226, 2002.

[23] L. Cheng, L. Zhao, V. M. Karbhari, G. A. Hegemier, and F. Seible, "Assessment of a steel-free fiber reinforced polymercomposite modular bridge system," Journal of Structural Engineering, vol. 131, no. 3, pp. 498-506, 2005.

[24] L. Cheng and V. M. Karbhari, "Fatigue behavior of a steel-free FRP-concrete modular bridge deck system," Journal of Bridge Engineering, vol. 11, no. 4, pp. 474-488, 2006.

[25] T. Keller, E. Schaumann, and T. Vallée, "Flexural behavior of a hybrid FRP and lightweight concrete sandwich bridge deck," Composites Part A: Applied Science and Manufacturing, vol. 38, no. 3, pp. 879-889, 2007.

[26] W. Alnahhal and A. Aref, "Structural performance of hybrid fiber reinforced polymer-concrete bridge superstructure systems," Composite Structures, vol. 84, no. 4, pp. 319-336, 2008.

[27] W. Alnahhal, A. Aref, and S. Alampalli, "Composite behavior of hybrid FRP-concrete bridge decks on steel girders," Composite Structures, vol. 84, no. 1, pp. 29-43, 2008.

[28] J. P. Hanus, L. C. Bank, and M. G. Oliva, "Combined loading of a bridge deck reinforced with a structural FRP stay-in-place form," Construction and Building Materials, vol. 23, no. 4, pp. 1605-1619, 2009.

[29] J. He, Y. Liu, A. Chen, and L. Dai, "Experimental investigation of movable hybrid GFRP and concrete bridge deck," Construction and Building Materials, vol. 26, no. 1, pp. 49-64, 2012.

[30] H. Xin, Y. Liu, J. He, H. Fan, and Y. Zhang, "Fatigue behavior of hybrid GFRP-concrete bridge decks under sagging moment," Steel and Composite Structures, vol. 18, no. 4, pp. 925-946, 2015.

[31] A. Fam and M. Nelson, "New bridge deck cast onto corrugated GFRP stay-in-place structural forms with interlocking connections," Journal of Composites for Construction, vol. 16, no. 1, pp. 110-117, 2012.
[32] M. Nelson and A. Fam, "Structural GFRP permanent forms with T-shape ribs for bridge decks supported by precast concrete girders," Journal of Bridge Engineering, vol. 18, no. 9, pp. 813-826, 2013.

[33] M. Nelson, A. Eldridge, and A. Fam, "The effects of splices and bond on performance of bridge deck with FRP stay-in-place forms at various boundary conditions," Engineering Structures, vol. 56, no. 6, pp. 509-516, 2013.

[34] R. Boles, M. Nelson, and A. Fam, "Durability of bridge deck with FRP stay-in-place structural forms under freeze-thaw cycles," Journal of Composites for Construction, vol. 19, no. 4, Article ID 04014070, 2015.

[35] B. Nicoletta, J. Woods, J. Gales, and A. Fam, "Postfire performance of gfrp stay-in-place formwork for concrete bridge decks," Journal of Composites for Construction, vol. 23, no. 3, pp. 04019015.1-04019015.15, 2019.

[36] J. Zhu and M. M. Lopez, "Performance of a lightweight GFRP composite bridge deck in positive and negative bending regions," Composite Structures, vol. 113, pp. 108-117, 2014.

[37] H. Tuwair, J. Volz, M. Eigawady, M. Mohamed, K. Chandrashekhara, and V. Birman, "Testing and evaluation of polyurethane-based GFRP sandwich bridge deck panels with polyurethane foam core," Journal of Bridge Engineering, vol. 21, no. 1, pp. 04015033.1-04015033.13, 2016.

[38] M. A. Al Ramahee, T. Chan, K. R. Mackie, S. Ghasemi, and A. Mirmiran, "Lightweight UHPC-FRP composite deck system," Journal of Bridge Engineering, vol. 22, no. 7, pp. 04017022.1-04017022.18, 2017.

[39] Y. Zuo, Y. Liu, and J. He, "Experimental investigation on hybrid GFRP-concrete decks with T-shaped perforated ribs subjected to negative moment," Construction and Building Materials, vol. 158, pp. 728-741, 2018.

[40] Y. Zuo, A. Mosallam, H. Xin, Y. Liu, and J. He, "Flexural performance of a hybrid GFRP-concrete bridge deck with composite T-shaped perforated rib connectors," Composite Structures, vol. 194, pp. 263-278, 2018.

[41] P. Bakeri, "Analysis and design of polymer composite bridge decks," M.Sc. thesis, Massachusetts Institute of Technology, Cambridge, MA, USA, 1989.

[42] M. Oliva, L. Bank, H. Bae, J. Barker, and S. Yoo, "FRP stay-inplace formwork and reinforcing for concrete highway bridge decks," in Proceedings of the FRPRCS-8, pp. 1-10, Patras, Greece, July 2007.

[43] M. Nelson and A. Fam, "Modeling of flexural behavior and punching shear of concrete bridge decks with FRP stay-inplace forms using the theory of plates," Journal of Engineering Mechanics, vol. 140, no. 12, pp. 04014095-1-04014095-12, 2014.

[44] M. Noël and A. Fam, "Design Equations for concrete bridge decks with FRP stay-in-place structural forms," Journal of Composites for Construction, vol. 20, no. 5, pp. 04016024-104016024-12, 2016.

[45] R. Lopez-Anido, P. Dutta, J. Bouzon, S. Morton, B. Shahrooz, and I. Harik, "Fatigue evaluation of FRP-concrete bridge deck on steel girders at high temperature," in Proceedings of the 44th International SAMPE Symposium, pp. 1666-1675, Long Beach, CA, USA, May 1999.

[46] K. Cho, S. Y. Park, S. T. Kim, J.-R. Cho, and B.-S. Kim, "Shear connection system and performance evaluation of FRPconcrete composite deck," KSCE Journal of Civil Engineering, vol. 14, no. 6, pp. 855-865, 2010.

[47] L. C. Bank, M. G. Oliva, H.-U. Bae, J. W. Barker, and S.-W. Yoo, "Pultruded FRP plank as formwork and 
reinforcement for concrete members," Advances in Structural Engineering, vol. 10, no. 5, pp. 525-535, 2007.

[48] S. Li, X. Zou, and J. Wang, "Comparative experimental and theoretical study on the interfacial shear behavior of two types FRP-concrete composite beams," Journal of Wuhan University of Technology (Transportation Science \& Engineering), vol. 37, no. 5, pp. 984-988, 2013, in Chinese.

[49] A. Fam and T. Skutezky, "Composite T-beams using reducedscale rectangular FRP tubes and concrete slabs," Journal of Composites for Construction, vol. 10, no. 2, pp. 172-181, 2006.

[50] R. El-Hacha and D. Chen, "Behaviour of hybrid FRP-UHPC beams subjected to static flexural loading," Composites Part B: Engineering, vol. 43, no. 2, pp. 582-593, 2012.

[51] H. Honickman and A. Fam, "Investigating a structural form system for concrete girders using commercially available GFRP sheet-pile sections," Journal of Composites for Construction, vol. 13, no. 5, pp. 455-465, 2009.

[52] A. Manalo, T. Aravinthan, H. Mutsuyoshi, and T. Matsui, "Composite behaviour of a hybrid FRP bridge girder and concrete deck," Advances in Structural Engineering, vol. 15, no. 4, pp. 589-600, 2012.

[53] H. Nordin and B. Täljsten, "Testing of hybrid FRP composite beams in bending," Composites Part B: Engineering, vol. 35, no. 1, pp. 27-33, 2004.

[54] J.-R. Cho, S. Y. Park, K. Cho, S. T. Kim, and B.-S. Kim, “Pullout test and discrete spring model of fibre-reinforced polymer perfobond rib shear connector," Canadian Journal of Civil Engineering, vol. 39, no. 12, pp. 1311-1320, 2012.

[55] L. Canning, L. Hollaway, and A. M. Thorne, "An investigation of the composite action of an FRP/concrete prismatic beam," Construction and Building Materials, vol. 13, no. 8, pp. 417426, 1999.

[56] J. Hulatt, L. Hollaway, and A. Thorne, "Short term testing of hybrid $\mathrm{T}$ beam made of new prepreg material," Journal of Composites for Construction, vol. 7, no. 2, pp. 135-144, 2003.

[57] W. Xue, C. Ge, Y. Tan, and Y. Wang, "Experimental studies on FRP-concrete composite deck with FRP perfobond shear connectors," Advances in FRP Composites in Civil Engineering, Springer, Berlin, Germany, pp. 219-223, 2011.

[58] C.-C. Chou and Y. Chen, "Push-off strength of steel girder to fiber-reinforced polymer deck connections," Journal of Constructional Steel Research, vol. 81, pp. 138-148, 2013.

[59] X. Zou, P. Feng, and J. Wang, "Perforated FRP ribs for shear connecting of FRP-concrete hybrid beams/decks," Composite Structures, vol. 152, pp. 267-276, 2016.

[60] J. S. Yuan and M. N. S. Hadi, "Bond-slip behaviour between GFRP I-section and concrete," Composites Part B: Engineering, vol. 130, pp. 76-89, 2017.

[61] S. Guo, B. Kong, C. Cai, J. Zhang, and X. Zeng, "Experimental study on the interface behavior of GFRP-concrete composite deck," Engineering Mechanics, vol. 34, no. 2, pp. 216-225, 2017, in Chinese.

[62] H. Huang, A. Li, L. Chen, C. Zeng, and M. Zhu, "Push-out tests for shear connectors in GFRP-concrete composite bridge deck slabs," Journal of Advanced Concrete Technology, vol. 16, no. 8, pp. 368-381, 2018.

[63] X. Zou, P. Feng, J. Wang, Y. Wu, and Y. Feng, "FRP stay-in-place form and shear key connection for FRP-concrete hybrid beams/ decks," Composite Structures, vol. 192, pp. 489-499, 2018.

[64] J. Gong, X. Zou, and P. Xia, "Experimental investigation of the natural bonding strength between stay-in-place form and concrete in FRP-concrete decks/beams," Applied Sciences, vol. 9, no. 5, p. 913, 2019.
[65] J. Di, L. Cao, and J. Han, "Experimental study on the shear behavior of GFRP-concrete composite beam connections," Materials, vol. 13, no. 5, Article ID 1067, 2020.

[66] M. Rajchel, M. Kulpa, and T. Siwowski, "Experimental study on a novel shear connection system for FRP-concrete hybrid bridge girder," Materials, vol. 13, no. 9, Article ID 2045, 2020.

[67] Y. Shao, Z. Wu, and J. Bian, "Wet-bonding between FRP laminates and cast-in-place concrete," in Proceedings of the International Symposium on Bond Behaviour of FRP in Structures, Hong Kong, China, December 2005.

[68] Y. Wang, Q. Hao, and J. Ou, "Study on bond behavior between FRP sheet with shear key and concrete," Journal of Shenyang Jianzhu University (Natural Science), vol. 23, no. 4, pp. 533-537, 2007, in Chinese.

[69] J.-R. Cho, K. Cho, S. Y. Park, S. T. Kim, and B.-S. Kim, "Bond characteristics of coarse sand coated interface between stayin-place fibre-reinforced polymer formwork and concrete based on shear and tension tests," Canadian Journal of Civil Engineering, vol. 37, no. 5, pp. 706-718, 2010.

[70] R. Lameiras, J. A. O. Barros, I. B. Valente, J. Xavier, and M. Azenha, "Pull-out behaviour of glass-fibre reinforced polymer perforated plate connectors embedded in concrete. Part II: prediction of load carrying capacity," Construction and Building Materials, vol. 169, pp. 142-164, 2018.

[71] Z. Xiong, Y. Liu, Y. Zuo, and H. Xin, "Experimental evaluation of shear behavior of pultruded GFRP perforated connectors embedded in concrete," Composite Structures, vol. 222, 2019. 